\title{
Prevalence of liver disease in cystic fibrosis
}

\author{
R Scott-Jupp, M Lama, M S Tanner
}

\begin{abstract}
To assess the prevalence, demography, and clinical features of liver disease among patients with cystic fibrosis the case notes of 524 patients of all ages who were attending the cystic fibrosis clinic were studied. Computer databases were used to establish the condition of the liver in a further $\mathbf{5 7 6}$ such patients. The overall prevalence of overt liver disease indicated by the presence of an enlarged liver or spleen (or both) was $4 \cdot 2 \%$. The age related prevalence rose to a peak in adolescence, and then fell in patients over 20 years old. The implied increase in mortality among those with liver disease was not explained by deaths from liver disease, which were rare. Male patients were significantly more affected than female, the ratio being 3:1 among adolescents. Increasing prevalence of liver disease in patients with cystic fibrosis is, therefore, not just a result of longevity.
\end{abstract}

Liver cirrhosis was recognised as a complication of cystic fibrosis in Andersen's original description in 1938, but until recently the importance of subclinical liver disease has been eclipsed by the more obvious respiratory and pancreatic signs and symptoms. ${ }^{1}$ More effective management of these has resulted in greatly improved survival, and so liver disease has become important to a larger number of patients.

The aetiology of focal biliary cirrhosis in cystic fibrosis is uncertain, ${ }^{3}$ but poor nutrition, ${ }^{4}$ inspissated bile, ${ }^{5}$ autoimmunity, ${ }^{6}$ and biliary tract obstruction ${ }^{7}$ have all been suggested.

Previous estimates of prevalence varied depending on the diagnostic criteria used. ${ }^{910}$ If cross sectional necropsy data are combined it looks as if prevalence rises steadily with age. $^{5} 1112$ There has been no study of clinically important liver disease in a large group of patients with cystic fibrosis spanning the entire age range.

A number of authors have shown that liver function tests are disordered in a high proportion of patients with cystic fibrosis and liver impairment, but that the degree of abnormality does not correlate with the extent of cirrhosis. ${ }^{5}$ 13-16 Some patients with obvious liver disease have normal test results, and there is a large number whose results are abnormal and whose true liver condition is uncertain. ${ }^{9} 10$

\section{Patients and methods}

The casenotes of all 524 patients attending adult and paediatric specialist cystic fibrosis clinics in four midlands centres (Birmingham, Nottingham, Peterborough, and Leicester) were reviewed. Subsequently the computer records of 576 patients with cystic fibrosis who were attending clinics in three northern centres (Manchester, Liverpool, and Leeds) were surveyed. All those with possible clinical evidence of liver disease were identified, and their casenotes were then examined. All the patients had undergone repeated abdominal examinations by physicians experienced in treating cystic fibrosis during routine visits to the clinic. From the records the presence of an enlarged liver or spleen (or both) was noted. If a spleen was described as 'palpable' it was considered to be enlarged. The liver was regarded as enlarged when it protruded $3 \mathrm{~cm}$ or more below the costal margin and was not apparently pushed down by hyperinflation of the lung. Radiological and ultrasound findings were not considered.

For the 524 patients in the first four centres only, those patients who had raised serum activities of aspartate transaminase, alanine aminotransferase, or $\gamma$-glutamyl transpeptidase at any time, but excluding transient increases in the activity of a single enzyme, were noted. These data were incomplete because only $388(74 \%)$ of the group had ever had their liver function tests done.

Evidence of symptomatic biliary disease was sought, but was considered only when symptoms of biliary colic were accompanied by radiographic or ultrasonographic evidence of gall stones. Policies for investigating asymptomatic biliary disease varied among clinics, so the true prevalence of 'silent' biliary disease could not be estimated.

Data about age at diagnosis of liver disease, mode of presentation, history of prolonged neonatal jaundice, family history, presence of oesophageal varices, and liver function tests were gathered. Where available, the age at death and mode of death of patients attending each of the four initial clinics were noted during the 10 years preceding the study.

The prevalence point was 1 June 1988 . The $\chi^{2}$ test was used to assess the significance of differences among groups.

\section{Results}

There were similar trends in the prevalence of clinically apparent disease in the data derived from casenotes in the midlands and those derived from databases in the northern survey. The data have therefore been combined to give a study population of 1100 patients with cystic
Correspondence to: Dr Scott-Jupp.

Accepted 21 January 1991 
Table 3 Ageatpresentation of liver disease $(n=39)$

\begin{tabular}{ll}
\hline $\begin{array}{l}\text { Age } \\
\text { (years) }\end{array}$ & $\begin{array}{l}\text { No } \\
\text { presenting }\end{array}$ \\
\hline 0 & 2 \\
4 & 2 \\
5 & 2 \\
6 & 3 \\
7 & 3 \\
8 & 1 \\
9 & 5 \\
10 & 3 \\
11 & 4 \\
12 & 2 \\
13 & 5 \\
14 & 4 \\
15 & 1 \\
17 & 1 \\
19 & 1
\end{tabular}

fibrosis. Of these, $46(4 \cdot 2 \%)$ had clinical liver disease. Eleven $(1 \cdot 0 \%)$ had an enlarged liver only, three $(0.3 \%)$ had an enlarged spleen only, and $32(2.9 \%)$ had enlargement of both liver and spleen. Cutaneous signs of liver disease were recorded in only two.

Oesophageal varices had been sought in 34/46 with clinical disease, and were detected in 11 . Of these, all had enlarged spleens, and six had bled at least once. There was no variceal bleeding in patients who did not have enlarged spleens. Six of 46 in the combined clinical group (13.0\%) had liver enzyme activities within the reference ranges, and four also had enlarged spleens.

No patient had jaundice or ascites at the time of the study.

The prevalence of abnormal liver enzyme activities in the absence of clinical disease could be estimated only for the midlands group of 524: 50 were identified $(9 \cdot 5 \%)$. These represented $12.9 \%$ of those who had had liver enzymes measured.

Clinically apparent and radiologically proved biliary disease was rare and restricted to the older age groups. Only six patients out of 1100 $(0.55 \%)$ were found: one of $183(0.5 \%)$ in the 16-20 age band, three of $107(2 \cdot 8 \%)$ in the 21-25 band, and two of $38(4 \cdot 6 \%)$ aged over 25 years.

AGE RELATED PREVALENCE (table 1)

There was a progressive rise in the prevalence of clinically apparent liver disease from $0.3 \%$ in the $0-5$ age group to a peak of $8.7 \%$ among those aged 16-20. Thereafter, instead of the expected progressive rise, there was a fall to only $4 \cdot 1 \%$ among 145 patients over 20 years of age. The same trend was seen when only those with splenomegaly were considered, or when those who had neither an enlarged spleen nor abnormal liver function tests were excluded.

The group with portal hypertension as indicated by an enlarged spleen had a mean age of 15.3 years (range 7-27), and those with oesophageal varices had a mean age of $17 \cdot 3$ years (range 9-27).

Biochemical abnormalities without clinical signs were more prevalent than overt disease (table 2), and showed a similar although less pronounced peak, rising to $16.0 \%$ in the $16-20$ age group, and falling to $11 \cdot 5 \%$ over 20 .

\section{SEX RELATED PREVALENCE}

Significantly more male patients were affected by clinical disease, both in the midlands and in the combined populations; $33 / 605(5 \cdot 4 \%)$ were affected overall compared with $13 / 495(2 \cdot 6 \%)$ of female patients, $(p<0.05)$. The difference was seen at all ages over 5 years, and was most pronounced in the 11-15 age group, in which three times as many boys as girls were affected. There were no significant differences between the sexes in the group with biochemical abnormalities only, but prevalence data for this group was incomplete.

\section{AGE AT PRESENTATION OF LIVER DISEASE}

Reliable information about the age at which liver disease first became clinically apparent was available for 39 of the 46 with clinical disease. (table 3). The mean age at presentation was $9 \cdot 8$ years (median 10.5).

\section{MODE OF PRESENTATION OF LIVER DISEASE} Of the 46 with clinical disease, it presented in 43 as an incidental finding on abdominal examination: 11 had enlarged liver only, three had enlarged spleen only, and in 29 both organs were enlarged. Two presented with abnormal liver enzyme activities and later progressed to overt disease; one presented with biliary pain. None of the patients presented with prolonged neonatal jaundice. Two presented with hepatosplenomegaly before the diagnosis of cystic fibrosis was made.

\section{SIBLINGS}

There were no sibling pairs within the total group of 46 patients with clinical liver disease, although nine of the 46 had one or more siblings with cystic fibrosis. Two, however, had siblings who had died and were known to have had liver disease. At least two had siblings with abnormal liver enzyme activities.

Table 1 Prevalence of clinical liver disease in 5 year age bands. Numbers are expressed as total number $(\%$ of number for age)

\begin{tabular}{|c|c|c|c|c|c|c|}
\hline & \multicolumn{5}{|l|}{ Age (years) } & \multirow[t]{2}{*}{ Total } \\
\hline & $0-5$ & $6-10$ & $11-15$ & $16-20$ & $\geqslant 21$ & \\
\hline \multirow{2}{*}{$\begin{array}{l}\text { No of patients with cystic fibrosis } \\
\text { No (\%) with clinical liver disease } \\
\text { No (\%) with enlarged spleen } \\
\text { No (\%) with either enlarged spleen } \\
\text { or abnormal liver function tests }\end{array}$} & $\begin{array}{l}318 \\
\quad 1 \\
0\end{array}(0 \cdot 3)$ & $\begin{array}{l}258 \\
9(3 \cdot 5) \\
6(2 \cdot 3)\end{array}$ & $\begin{array}{l}196 \\
14(7 \cdot 1) \\
11(5 \cdot 6)\end{array}$ & $\begin{array}{l}183 \\
16(8 \cdot 7) \\
14(7 \cdot 6)\end{array}$ & $\begin{array}{r}145 \\
6(4 \cdot 1) \\
4(2 \cdot 8)\end{array}$ & $\begin{array}{l}1100 \\
46(4 \cdot 2) \\
35(3 \cdot 2)\end{array}$ \\
\hline & $1(0 \cdot 3)$ & $7(2 \cdot 7)$ & $12(6 \cdot 1)$ & $16(8 \cdot 7)$ & $6(4 \cdot 1)$ & $42(3 \cdot 8)$ \\
\hline
\end{tabular}

Table 2 Prevalence of biochemical liver disease without clinical signs in midlands centres; 136 (26\%) of the total had not had liver function tests carried out. Numbers are expressed as total number (\% of number for age)

\begin{tabular}{|c|c|c|c|c|c|c|}
\hline & \multicolumn{5}{|c|}{ Age (years) } & \multirow[t]{2}{*}{ Total } \\
\hline & $0-5$ & $6-10$ & $11-15$ & $16-20$ & $\geqslant 21$ & \\
\hline $\begin{array}{l}\text { No of patients with cystic fibrosis } \\
\text { No (\%) with biochemical liver disease }\end{array}$ & 177 (5.6) & $125(8 \cdot 0)$ & $\begin{array}{l}89 \\
11(12 \cdot 4)\end{array}$ & $\begin{array}{l}81 \\
13(16 \cdot 0)\end{array}$ & 52 & $\begin{array}{r}524 \\
50(9 \cdot 5)\end{array}$ \\
\hline
\end{tabular}


CAUSE OF DEATH

The causes of death among those attending the midlands clinics over the past 10 years were reliably ascertained in $80 \%$. For the others records were unavailable, or death had occurred at home and the precise mode had not been recorded. There were 77 deaths during this period ( 31 male, 46 female), and their mean age was 13.9 years. Only two patients died from acute variceal haemorrhage, and only four from acute liver failure. The mean age at death of these six (three male, three female) was $10 \cdot 8$ years. The remainder died primarily from respiratory causes, but at least six of these had some degree of liver disease.

\section{Discussion}

There have been no previous systematic attempts to assess the clinical prevalence of liver disease among patients with cystic fibrosis across the entire age range in a substantial population. Feigelson et al, using a variety of criteria, found evidence of cirrhosis in nine of 50 patients with cystic fibrosis between 1 and 20 years old. ${ }^{16}$ Stern et al described 15 cases with symptomatic liver disease in a population of $693(2 \cdot 2 \%) .{ }^{14}$ Schwarz et al reported nine cases of overt liver disease among 204 patients all less than 13 years old $(4 \cdot 4 \%) .{ }^{17}$ More recently, Nagel et al reported either biochemical or overt liver disease in 57 of 233 patients over 15 years old $(24 \cdot 5 \%){ }^{18}$

Necropsy studies have shown overall rates of abnormal histological appeareances of the liver of $12 \%,{ }^{19} 22 \%,{ }^{5}$ and $29 \cdot 5 \%$. $^{11}$ The latter series $(n=146)$ suggested an increasing prevalence with age from $10.8 \%$ at less than 3 months to $26.8 \%$ at over 1 year. Vawter and Schwachman found focal biliary changes in 21 of 29 patients who died after the age of 24 years $(72 \%) .{ }^{12} \mathrm{Nec}-$ ropsy data may not reflect the true age related prevalence as the presence of liver disease may have contributed to death. None of the published necropsy studies relate the histopathological findings to clinical condition, or to radiological or biochemical abnormalities.

Varying estimates of the prevalence of abnormalities shown on ultrasound scanning have also been reported. Willi et al performed scans in 24 unselected patients and found abnormalities in $22(92 \%)$, of whom 10 had specific liver abnormalities. ${ }^{20}$ Graham et al (in an adult series) found hepatomegaly in 23 of $35(66 \%)$ and abnormal echogenicity in 11 of $35(31 \%),{ }^{21}$ and Wilson-Sharp et al found hepatic abnormalities in $23 \%$ of children. ${ }^{22}$

Data on the results of examination of liver biopsy specimens in patients with cystic fibrosis are scarce, although Dietzsch et al found histological evidence of liver disease in 15 of 84 children who underwent needle biopsy $(18 \%))^{15}$ Not all those whose biopsy specimens were abnormal had either clinical or biochemical evidence of liver disease. Trying to identify subclinical liver disease by biopsy is impossible to justify in the absence of any treatment, except in assessment for transplantation.

Thus the assumption of a rising prevalence of liver disease with age in cystic fibrosis is based mainly on necropsy series. ${ }^{23}$ In the present study the prevalence of clinically overt disease in 1100 patients with cystic fibrosis was $4.4 \%$, similar to some quoted estimates. ${ }^{10} 23$ This is likely to be an underestimate of the true prevalence of focal biliary cirrhosis, as the histopathological changes may precede enlargement of the liver or the development of portal hypertension.

The presence of an enlarged liver in isolation, with no other evidence of liver disease, should be interpreted with caution because this may be the result of depression of a normal liver below the costal margin by hyperinflated lungs, rather than true enlargement. Measuring the liver span by percussion is difficult in patients with cystic fibrosis because the chest is frequently hyperresonant throughout. In our series, however, only four patients had isolated liver enlargement with neither splenomegaly nor abnormal liver function tests, and when these were excluded the same trends in age and sex prevalence were seen.

Liver disease was relatively uncommon before the age of 10 years. Some of the younger patients may have had hepatic steatosis related to poor nutrition rather than cirrhosis. ${ }^{24}$ Thereafter, instead of the expected progressive rise into adult life, there was a peak during adolescence followed by a fall in prevalence over the age of 20 years.

There are two possible explanations for this observation. Firstly, it may be an unexplained cohort effect, and further longitudinal studies would show whether the prevalence peak shifts into adult life. Alternatively, because liver disease in cystic fibrosis is irreversible, this trend can be explained by an increase in mortality in the teenage years among those with liver disease. Our review of mortality records for the preceding 10 years showed that only $7 \cdot 8 \%$ of deaths could be attributed directly to liver disease, either hepatocellular failure or portal hypertension. It may therefore be that the presence of liver disease increases the likelihood of premature respiratory death in teenage patients with cystic fibrosis. The rarity of hepatocellular failure as a cause of death may be explained by the histopathology of focal biliary cirrhosis, in which the hepatic parenchyma is left largely intact. $^{34}$

The sex distribution of overt disease showed an unexpected preponderance of male patients. No other manifestation of cystic fibrosis shows such a sex difference. It cannot be attributed to the action of sex hormones, as the onset was usually prepubertal. Recently, Becker et al showed that female patients with cystic fibrosis had significantly more cholesterol saturation of bile than male patients, but this difference was seen only after puberty. There is reported to be a higher mortality from cystic fibrosis among female compared with male patients in the United Kingdom as a whole, ${ }^{2}$ and it is possible that increased mortality among girls with liver disease explains our findings.

Although these data are derived from patients attending specialist cystic fibrosis clinics, and may thus be somewhat selected, they include most of the patients with cystic fibrosis living in the areas served by the clinics. No patients were 
referred specifically because of liver disease. There is no reason to suppose that the observed trends should be any different for patients who were not attending the clinics.

The findings in the 'biochemical' group, derived from the smaller midlands population only, should be interpreted with caution as there was no consistent policy of monitoring liver enzyme activities among the clinics. Some patients had never had liver function tests done, and in others, increased activities may have been the result of causes other than developing cirrhosis. Liver function tests were carried out more often in older patients. Despite the incomplete data the same age prevalence trend was seen as in patients with overt disease.

Like other authors, we found an inconsistent relationship between hepatosplenomegaly and abnormal liver enzyme activities. Kattwinkel et $a l$ in their study of liver enzyme activities in patients with cystic fibrosis compared with age matched controls found that 15/40 (38\%) had. raised alkaline phosphatase liver isoenzyme activity. ${ }^{13}$ They also found raised $\gamma$-glutamyl transpeptidase, aspartate aminotransferase, and alanine aminotransferase activities in a similar proportion of patients, but only six of 11 patients with palpable livers had abnormal tests, while 11/38 whose livers were not palpable had abnormal tests. We therefore doubt the value of routine monitoring of liver enzyme activities in patients with cystic fibrosis. No evidence has been published to establish the value of other biochemical or haematological tests, including dynamic tests of liver function such as caffeine clearance, in predicting the later occurrence of overt disease.

Subclinical biliary disease is thought to be common among adults with cystic fibrosis. In one study 17 of 23 adults with abnormal liver enzyme activities had abnormalities on biliary imaging, ${ }^{18}$ and this was suggested to be the primary hepatobiliary lesion in cystic fibrosis. ${ }^{7}$ We found symptoms of biliary disease to be rare.

The mode of presentation of liver disease was by routine abdominal examination in most patients, and in only two of 46 of the clinical group (4\%) was the development of overt disease predicted by abnormal liver function tests. We found no strong evidence of familial concordance as reported by Schuster et al. ${ }^{26}$

As expected, $20 \%$ of those with overt disease had oesophageal varices although, because not all patients had been recently investigated, the true incidence may have been higher. Enlargement of the spleen seems to predict those at risk from haemorrhage.

In conclusion, these data suggest that the prevalence of liver disease in cystic fibrosis peaks during adolescence, affects male more than female patients, and seems to be associated with earlier death. Those with liver disease may thus form an identifiable group with a worse prognosis who warrant more aggressive treatment. Poor nutritional state associated with liver disease may contribute to the shorter life span, but data are lacking. Clinical signs are probably a late sign of liver disease, but results of liver function tests are unreliable. The cause, future changes in prevalence, and the prognosis of liver disease in cystic fibrosis demand further study.

We thank the Cystic Fibrosis Research Trust for funding this study. We also thank colleagues in the cystic fibrosis clinics in Leicester, Nottingham, Birmingham, Peterborough, Leeds, Liverpool, and Manchester for allowing us to search their records, and in particular Dr EJ Hiller, Dr P Weller, and Dr J Kuzemko for help in setting up the study.

1 Andersen DH. Cystic fibrosis of the pancreas. Am $\mathcal{F}$ Dis Child 1938;56:344-99.

2 Britton JR. Effects of social class, sex, and region of residence on age at death from cystic fibrosis. $B M \mathcal{F}$ 1989;298:483-7.

3 Bodian M. Fibrocystic disease of the pancreas. A congenital disorder of mucus production-mucosis. London: William Heinemann, 1952:106-10.

4 Webster R, Williams H. Hepatic cirrhosis associated with fibrocystic disease of the pancreas. Arch Dis Child 1953;28: 343-50.

5 di Sant'Agnese PA, Blanc WA. A distinctive type of biliary cirrhosis of the liver associated with cystic fibrosis of the pancreas. Pediatrics 1956;18:387-409.

6 Mieli-Vergani G, Psacharopoulos HT, Nicholson AM, et al. Immune responses to liver membrane antigens in patients with cystic fibrosis and liver disease. Arch Dis Child 1980; 55:696-701.

7 Gaskin KJ, Waters DLM, Howman-Giles R, et al. Liver disease and common bile-duct stenosis in cystic fibrosis. disease and common bile-duct

8 Maurage C, Lenaerts C, Weber A, Brochu P, Yousef I, Roy CC. Meconium ileus and its equivalent as a risk factor for the development of cirrhosis: an autopsy study in cystic fibrosis. F Pediatr Gastroenterol Nutr 1989;9:17-20

9 Isenberg JN. Cystic fibrosis: its influence on the liver, biliary tree, and bile salt metabolism. Semin Liver Dis 1982;2: 302-13.

10 Park RW, Grand RJ. Gastrointestinal manifestations of cystic fibrosis: a review. Gastroenterology 1981;81:1143-61.

11 Oppenheimer EH, Esterly JR. Hepatic changes in young infants with cystic fibrosis: possible relation to focal biliary cirrhosis. 7 Pediatr 1975;86:683-9.

12 Vawter GF, Schwachman H. Cystic fibrosis in adults: an autopsy study. Pathol Annu 1979;14:357-82.

13 Kattwinkel J, Taussig LM, Statland BE, Verter JI. The effects of age on alkaline phosphatase and other serologic liver function tests in normal subjects and patients with liver function tests in normal subjects and
cystic fibrosis. $f$ Pediatr 1973;82:234 42 .

14 Stern RC, Stevens DP, Boat TF, Doershuk CF, Izant RJ, Matthews LW. Symptomatic hepatic disease in cystic Matthews LW. Symptomatic hepatic disease in cystic
fibrosis: incidence, course, and outcome of portal systemic fibrosis: incidence, course, and outcome of

15 Dietzsch HJ, Gottschalk B, Hinkel GK, Roschlav G. The value of bioptic follow-up examinations for controlling the course of liver involvement in cystic fibrosis. In: Sturgess JM, ed. Perspectives in cystic fibrosis. Toronto: Canadian Cystic Fibrosis Foundation, 1980:220-5.

16 Feigelson J, Pecau Y, Cathelineau L, Navarro J. Additional data on hepatic function tests in cystic fibrosis. Acta Paediatr Scand 1975;64:337-44.

17 Schwarz HP, Kraemer R, Thurnheer U, Rossi E. Liver involvement in cystic fibrosis. Helv Paediatr Acta 1978;33: involveme

18 Nagel RA, Westaby D, Javaid A, et al. Liver disease and bile duct abnormalities in adults with cystic fibrosis. Lancet duct abnormaliti.

19 Luftner J, Scheibner K, Woeckel W. Zur hepatischen Manifestation der Mukoviszidose. Zentralbl Allg Pathol 1977; 121:195-200.

20 Willi UV, Reddish JM, Teele RL. Cystic fibrosis: its characteristic appearance on abdominal ultrasonography. AfR 1980;134:1005-10.

21 Graham N, Manhire AR, Stead RJ, Lees WR, Hodson ME, Batten JC. Cystic fibrosis: ultrasonographic findings in the pancreas and hepatobiliary system correlated with clinical data and pathology. Clin Radiol 1985;36:199-203.

22 Wilson-Sharp RC, Irving HC, Brown RC, Chalmers DM, Littlewood JM. Ultrasonography of the pancreas, liver, and biliary system in cystic fibrosis. Arch Dis Child 1984;59: 923-6.

23 Roy CC, Weber AM, Morin CL, et al. Hepatobiliary disease in cystic fibrosis: a survey of current issues and concepts.

24 Thaler H. Relation of steatosis to cirrhosis. Clinics in Gastroenterology 1975;48:273-80.

25 Becker M, Staab D, Leiss O, Von Bermann K. Biliary lipid Becker $M$, Staab $D$, Leiss $O$, Von Bermann $K$. Biliary lipid
composition in patients with cystic fibrosis. $\mathcal{F}$ Pediatr

26 Schuster SR, Schwachman H, Toyama WM, Rubino A, Taik-Khaw $\mathrm{K}$. The management of portal hypertension in cystic fibrosis. F Pediatr Surg 1977;12:201-6. 